\title{
Congenital short QT syndrome: Landmarks of the newest arrhythmogenic cardiac channelopathy
}

\author{
Andrés Ricardo Pérez-Riera ${ }^{1}$, Adail Paixão-Almeida ${ }^{2}$, Raimundo Barbosa-Barros ${ }^{3}$,
} Frank G. Yanowitz ${ }^{4}$, Adrian Baranchuk ${ }^{5}$, Sergio Dubner ${ }^{6}$, Antônio Carlos Palandri Chagas ${ }^{7}$

${ }^{1} \mathrm{ABC}$ 's Faculty of Medicine, ABC Foundation, Cardiology Discipline,

Electro-Vectorcardiogram Sector, Santo André, São Paulo, Brazil

${ }^{2}$ Cardiology and Electrocardiology Service, UNIMEC Hospital - Vitoria da Conquista, Bahia, Brazil

${ }^{3}$ Coronary Center of the Hospital de Messejana Dr Carlos Alberto Studart Gomes. Fortaleza, Ceará, Brazil

${ }^{4}$ Department/Division: Department of Medicine/Cardiology/Geriatrics,

University of Utah School of Medicine and Intermountain Healthcare, Salt Lake City, Utah

${ }^{5}$ Queen's University, Kingston, Ontario, Canada

${ }^{6}$ Clinical and Maternidad Suizo Argentina, Buenos Aires, Argentina

${ }^{7} \mathrm{ABC}$ 's Faculty of Medicine, ABC Foundation, Cardiology Discipline, Santo André, Brazil

\begin{abstract}
Congenital or familial short QT syndrome is a genetically heterogeneous cardiac channelopathy without structural heart disease that has a dominant autosomal or sporadic pattern of transmission affecting the electric system of the heart. Patients present clinically with a spectrum of signs and symptoms including irregular palpitations due to episodes of paroxysmal atrial fibrillation, dizziness and fainting (syncope) and/or sudden cardiac death due to polymorphic ventricular tachycardia and ventricular fibrillation.

Electrocardiographic (ECG) findings include extremely short QTc intervals (QTc interval $\leq 330 \mathrm{~ms}$ ) not significantly modified with heart rate changes and $T$ waves of great voltage with a narrow base. Electrophysiologic studies are characterized by significant shortening of atrial and ventricular refractory periods and arrhythmias induced by programmed stimulation.

A few families have been identified with specific genotypes: 3 with mutations in potassium channels called SQT1 $\left(I_{k s}\right)$, SQT2 $\left(I_{k r}\right)$ and SQT3 $\left(I_{k 1}\right)$. These 3 potassium channel variants are the "genetic mirror image" of long QT syndrome type 2, type 1 and Andersen-Tawil syndrome respectively because they exert opposite gain-of-function effects on the potassium channels in contrast to the loss-of-function of the potassium channels in the long QT syndromes. Three new variants with overlapping phenotypes affecting the slow inward calcium channels have also been described. Finally, another variant with mixed phenotype affecting the sodium channel was reported. This review focuses the landmarks of this newest arrhythmogenic cardiac channelopathy on the main clinical, genetic, and proposed ECG mechanisms. In addition therapeutic options and the molecular autopsy of this fascinating primary electrical heart disease are discussed. (Cardiol J 2013; 20, 5: 464-471)
\end{abstract}

Key words: congenital short QT syndrome, historical landmarks, channelopathies

Address for correspondence: Andrés Ricardo Pérez-Riera, MD, PhD, Rua Sebastião Afonso 885 Zip Code: 04417-100 Jardim Miriam, São Paulo City - Capital, Brazil, tel: 55 (011) 5621-2390, fax: 55 (011) 5625-7278, e-mail: riera@uol.com.br 


\section{Introduction}

Congenital short QT syndrome (SQTS) is a rare inherited channelopathy without structural heart disease. It is an autosomal dominant, primary electrical disorder with a low degree of penetrance. It has a characteristic clinical-electrocardiographic-electrophysiological phenotype consisting of irregular palpitations due to the frequent episodes of paroxysmal atrial fibrillation (AF), dizziness and/or sudden cardiac death (SCD). Affected individuals usually have a positive family history of syncope or SCD in first or second degree young relatives (younger than 40 years of age) with autopsy negative SCD.

Resting electrocardiograms (ECGs) have very short and uniform QT/QTc intervals (QTc inter$\mathrm{val} \leq 330 \mathrm{~ms}$ with the exception of the calcium-dependent variants 4 and 5), absent or minimal ST segments, interval from J point to $T$ wave peak (Jp-Tp) measured in the precordial lead with the $\mathrm{T}$ wave of greatest amplitude $<120 \mathrm{~ms}$, possible tall $\mathrm{T}$ waves with narrow base similar to the $\mathrm{T}$ wave of moderate hyperkalemia ("desert tent $\mathrm{T}$ waves"), frequent early repolarization pattern [1], prolongation of Tpeak-Tend interval, possible presence of prominent $\mathrm{U}$ waves, and very frequent paroxysmal AF. Additionally, the ECG response to exercise is characterized by a discrete QT interval reduction with increases in heart rate.

Intracardiac electrophysiological studies (EPS) show extremely short atrial refractory period $(<140 \mathrm{~ms})$ and ventricular refractory period $(<150 \mathrm{~ms})$, as well as an increased inducibility of $\mathrm{AF}$ and ventricular fibrillation (VF). Atrial refractory periods of $<140 \mathrm{~ms}$ and ventricular effective refractory periods of $<150 \mathrm{~ms}$ are highly suspicious of SQTS.

Finally, data from autopsies do not reveal any evidence of structural heart disease. A molecular autopsy, defined as whole-genome sequencing performed post-mortem for patients who have died suddenly of unknown causes, is mandatory in the cases where young people dying suddenly present with a normal heart ("mors sine materia").

\section{Major landmarks of the more recent cardiac channelopathy}

In 1993, Algra et al. [2], after analyzing almost 670 registries of consecutive Holter ECG recordings, concluded that the increase in risk of SCD was present not only in cases of QT interval prolongation, but also in the cases of QT interval shortening below $400 \mathrm{~ms}$.
In 1999, Bjerregaard and Gussak [3] was the first to discover this entity in a premature 4-year-old African American girl who presented developmental retardation and several episodes of cardiac arrest. Her ECG had gradual and paradoxical shortening of the QT interval with decreases in heart rate until reaching values of $216 \mathrm{~ms}$ (deceleration-dependent QT interval shortening) and transient anomalies of the $T$ wave. She died prematurely, and the authors published their observations emphasizing the heart rate deceleration-dependent QT interval shortening. They speculated that this represented a new electrical phenomenon dependent on the inwardly-rectifying potassium channel $\left(I_{\mathrm{K} \text { Arch }}\right)$ activation caused by an intense vagal discharge and responsible for bradycardia and QT interval shortening. They postulated that her death could be related to the short QT interval [4]. We think that this speculation is unlikely, because $I_{\mathrm{K} \text { Arch }}$ channels are not expressed in ventricular cells. They are expressed primarily in the sinoatrial node, atrioventricular (AV) node, and atrial muscle cells causing hyperpolarization and action potential shortening, as well as negative chronotropic and dromotropic effects. $I_{\mathrm{K} \text { Arch }}$ together with $\mathrm{I}_{k \text { Ado }}$ belongs to the inward-rectifying $\mathrm{K}(+)$ (Kir) channel family. These are activated by muscarinic $\left(\mathrm{M}_{2}\right)$ and purinergic type 1 receptors via GTP regulatory $(G)$ protein signal transduction.

In February 1999, a 17-year-old previously healthy Caucasian girl underwent laparoscopic cholelithiasis at the Anderson Hospital in Maryville, Illinois USA. At the end of the procedure she developed paroxysmal AF with rapid ventricular response (150-200 bpm) and acute pulmonary edema. DC cardioversion was conducted with success, and she was discharged on digoxin in sinus rhythm. After 45 days she had recurrence of $\mathrm{AF}$ and was referred to Dr Bjerregaard who noticed that she had an extremely short QTc (225 $\mathrm{ms})$. Therapy was started with propafenone. For 6 months she remained asymptomatic without recurrence of $\mathrm{AF}$, and propafenone was discontinued. Two months later, after a new episode of AF, treatment with propafenone was re-started. For more than 4 years she remained asymptomatic on propafenone without any evidence of AF. In August 2003, after the publication by Gussak et al. [4], she underwent an electrophysiology study with induction of $\mathrm{VF}$ and received an intracardiac defibrillator (ICD).

Gussak et al. [5] presented a family where some of its members were carriers of persistent short QT intervals: a 17-year-old teenager with QT interval of $240 \mathrm{~ms}$ that suffered several episodes of paroxysmal 
$\mathrm{AF}$ requiring electric cardioversion; the 21-year-old brother was asymptomatic; the 51-year-old mother had a history of sustained palpitations and $\mathrm{AF}$; and the maternal grandfather. An 84-year-old Italian Caucasian (QT interval of $240 \mathrm{~ms}$ ) was in chronic AF related to hypertension and coronary artery disease and died of cerebral embolism years later. The authors described other manifestations of abnormally short QT intervals and mentioned the possible arrhythmogenic potential of this finding.

Gaita et al. [6] described several members of 2 different families with symptoms of syncope, palpitations and aborted cardiac arrest in the presence of positive family histories of SCD. All the patients had constant short QT/QTc intervals (QT interval $\leq 280 \mathrm{~ms}$ and $\mathrm{QTc} \leq 300 \mathrm{~ms}$ ). Finally, during an electrophysiology study, they verified that the refractory periods, both atrial and ventricular, were very short, thus causing vulnerability to both atrial and VF. The autopsy did not reveal any underlying structural heart disease.

The same year, Schrimpf et al. [7] published the first experience of ICD implant in 5 members of 2 European families, revealing a high rate of inappropriate shocks by T-wave over sensing due to the high voltage of these waves.

In January 2004, Brugada et al. [8], working in the Masonic Medical Research Laboratory, described for the first time the genetic basis of this new entity characterized by SCD in infants, children, teenagers and young adults with short QT/QTc intervals. The entity is caused by 2 missense mutations in the KCNH2 (HERG) gene producing a dramatic gain in function in the rapid outward rectifier potassium channel known as $I_{\mathrm{kr}}$ and leading to a heterogeneous shortening of action potentials and consequently of QT/QTc intervals. The authors speculated that this could be another cause for the so-called sudden infant death syndrome (SIDS). This variant was called SQT1. The entity is the allelic mirror image of the congenital long QT syndrome variant 2 or LQT2.

In May 2004, Bellocq et al. [9] from Laboratoire de Physiopathologie et de Pharmacologie Cellulaires et Moléculaires, Nantes, France, showed the genetic heterogeneity of the new entity by identifying a mutation in the KCNQ1 gene (g919c substitution) that causes an acceleration in the kinetics of function activation of the slow outward rectifier potassium channel $I_{\mathrm{ks}}$. This variant was called SQT2. It is the mirror image of congenital long QT syndrome type 1 or LQT1.

In November 2004, Viskin et al. [10] from the Department of Cardiology, Tel Aviv University's
Sackler Faculty of Medicine, Israel, compared QT interval duration in 28 patients with idiopathic VF (17 men) with normal controls. Short QT was defined as QTc $\leq 360 \mathrm{~ms}$ for men and $\leq 370 \mathrm{~ms}$ for women. The authors concluded that shorter QTc intervals values are commonly seen in male patients with idiopathic VF. However, short QTc values are not rare among healthy adults, especially at slow heart rates. Consequently, until today there is no answer to the authors' question: Is idiopathic VF a short QT syndrome? A short QT interval has also been noticed in some other arrhythmic syndromes including Brugada syndrome and early repolarization syndrome, but the role of a short QT interval in these settings is not yet known [11].

In April 2005, Priori et al. [12] from Pavia University, Italy, identified a new familial variant called SQT3 which, unlike the previous variants, presented with asymmetrical high voltage $T$ waves [13]. This new variant was caused by a mutation in the KCNJ2 or kir2.1 gene by G514A substitution that encodes the inward rectification of the $I_{\mathrm{k} 1}$ channel (human inwardly rectifying potassium channel KIR2). This mutation causes acceleration of the final phase of repolarization (gain in function), thus shortening the duration of the action potential and QT interval of ECG. This variant is the counterpart of the Andersen-Tawil syndrome type 1 , also caused by mutation in the $\mathrm{KCNJ} 2$ or kir2.1 gene and manifested by familial periodical paralysis, cardiac arrhythmias and development anomalies with micrognathia, dental anomalies, low-set ears, hypertelorism, clinodactyly, and possible short height and scoliosis.

The same year (2005), we presented the first case in Latin America [14], with complete right bundle branch block, and using the vectorcardiogram method, we showed that the T-loop limbs are asymmetrical (secondary T-loop) because the velocity of inscription of the efferent limb is slower (dashes closer to each other) than the afferent limb inscription velocity, as seen in the normal T-loop (Fig. 1).

The Holter monitoring demonstrated the presence of paroxysmal AF (Figs. 2, 3).

In January 2007, Antzelevitch et al. [15], from the Masonic Medical Research Laboratory in Utica, New York, identified a new variant with a not-so-short QTc interval ( $\leq 360 \mathrm{~ms}$ ) associated with the Brugada syndrome. Unlike the previous cases that affect potassium channels, this variant was associated with a loss of function in the slow inward calcium channel or L-type channel. The mutations are of the missense type in CACNA1C (A39V and 


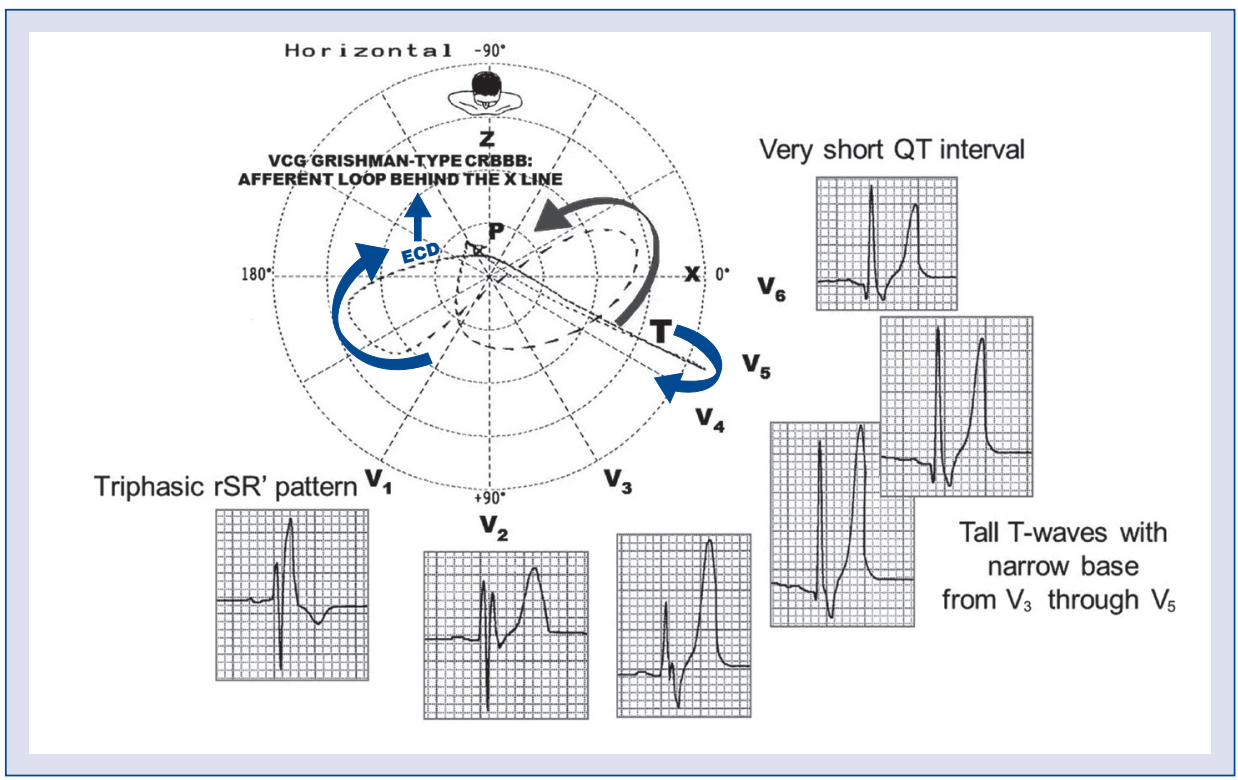

Figure 1. Electro-vectorcardiographic (ECG/VCG) correlation in horizontal plane in a patient with congenital short QT syndrome (SQTS). The precordial leads of ECG show the typical features of complete right bundle branch block (CRBBB): QRS duration > $120 \mathrm{~ms}$, triphasic $r S R^{\prime}$ pattern in $\mathrm{V}_{1}$ and wide final $\mathrm{S}$ waves in left precordial lead $\mathrm{V}_{5}-\mathrm{V}_{6}$. Additionally, tall $T$ waves with narrow bases from $V_{3}$ to $V_{5}$ and very short QT/QTc intervals are observed. The QRS loop of VCG shows CRBBB: QRS-loop duration > $120 \mathrm{~ms}$ (This corresponds to 60 or more dashes, where 1 dash $=2 \mathrm{~ms}$ ); "Grishman" or Kennedy VCG type I (afferent limb behind the X orthogonal line). Additionally, terminal appendage after $60 \mathrm{~ms}$ with delay (slow recording end conduction delay (ECD) located on right quadrants in "glove finger" shape. T-loop is asymmetric with the afferent limb having slower conduction velocity compared to the efferent one (less distance between dashes indicates the slower conduction velocity in the area of RVOT). This observation shows that the $\mathrm{T}$ wave is not symmetrical (pseudo-symmetrical).

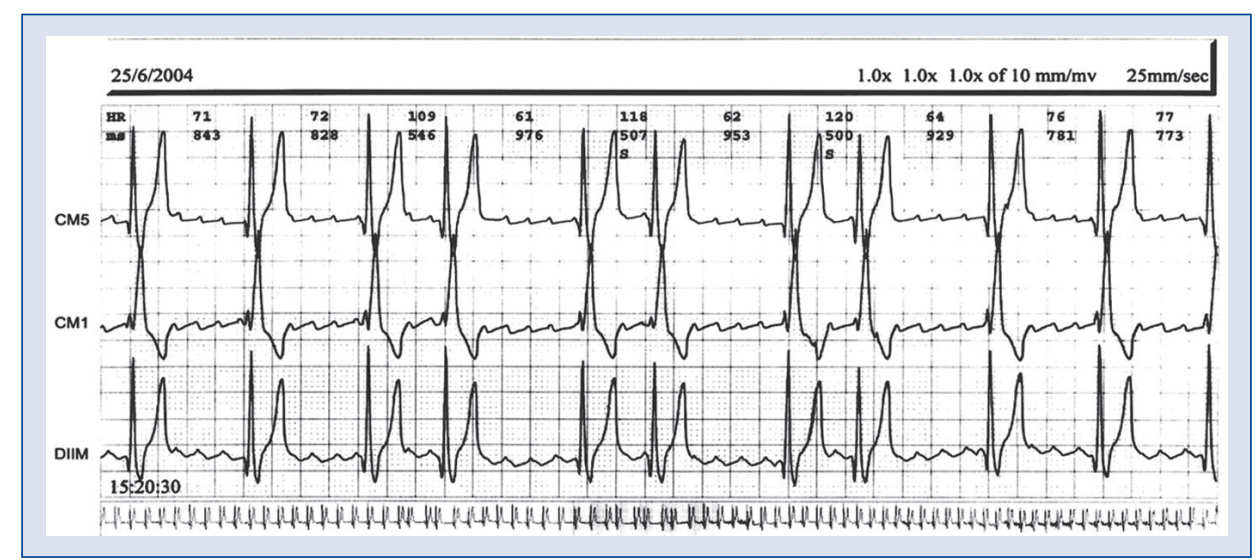

Figure 2. Holter recording in a patient with short QT syndrome. There is a short period of paroxysmal atrial fibrillation. In this moment, the patient complained of irregular palpitations.

G490R) and CACNB2 (S481L) that encode alpha-1 and beta2b subunits of the slow L-type $\mathrm{Ca}^{2+}$ channel (LTCC). This was the first report on mutations in the genes that encode the L-type calcium channel and is associated with a familial syndrome of SCD in which a Brugada syndrome phenotype is combined with discretely shorter QT intervals. These are considered the SQT4 and SQT5 variants. Genetic defects in the LTCC may also cause Timothy syndrome, Brugada syndrome, in $\mathrm{Ca}(\mathrm{v}) 1.31$ associated with $\mathrm{X}$-linked retinal disorder and deafness, and a mutation in $\mathrm{Ca}(\mathrm{v}) 1.4$ causing diseases such as 


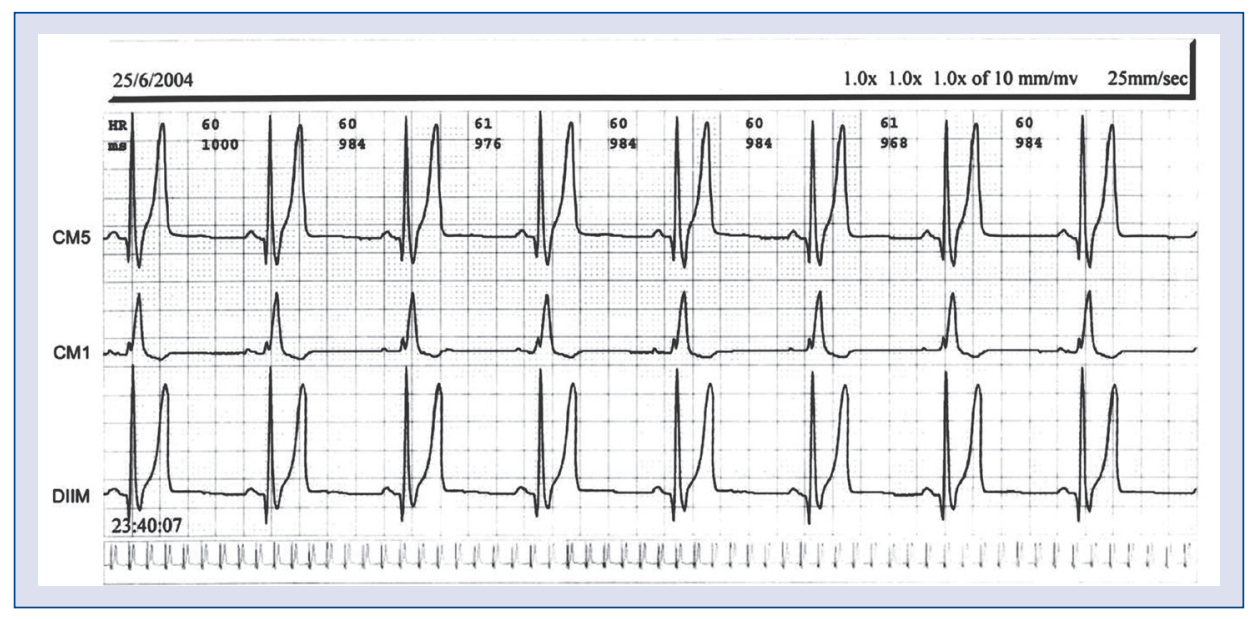

Figure 3. Holter recording in a patient with congenital short QT syndrome with spontaneous sinus rhythm during the same recording (8 $\mathrm{h}$ later).

an incomplete form of congenital stationary night blindness.

Anttonen et al. [16] demonstrate an increased transmural dispersion of repolarization (TDR) and its electrocardiographic counterpart T-wave peak to T-wave end interval (TPE) in SQTS patients that in part explain increased vulnerability of SQTS patients to ventricular arrhythmias.

In May 2011, Templin et al. [17] from the Cardiovascular Center, University of Zurich, Switzerland, identified what they called the SQT6 variant, characterized by mutations in the CACNA2D1 gene that encodes the $\alpha(2) \delta$-1 subunit of the LTCC. The ECG of the affected member of a single family revealed a QT interval of $317 \mathrm{~ms}$ (329 ms QTc) associated with tall, narrow and symmetrical $\mathrm{T}$ waves. The EPS showed short ventricular refractory periods and increased vulnerability to induce VF.

Gollob et al. [18] published a systematic review based on a comprehensive analysis of 61 reported cases in the English language from the MEDLINE database in order to develop diagnostic criteria for congenital SQTS to facilitate clinical evaluation of suspected cases. The score was established on the basis of clinical, electrocardiographic, and genetic criteria as follows:

- Two electrocardiographic criteria: QT interval corrected by Bazett's formula $<370 \mathrm{~ms}$ (1 point), $<350 \mathrm{~ms}$ ( 2 points) and $<330 \mathrm{~ms}$ ( 3 points) and $\mathrm{J}$ point-T peak interval duration in ms: Jp-Tp, < $120 \mathrm{~ms}$ (1 point);

- Four personal clinical history dates: history of sudden cardiac arrest (2 points), documented polymorphic VT or VF (2 points), unexplained syncope (1 point) and/or AF (1 point);

- Three family history parameters: first-or second-degree relative with high probability of SQTS (2 points), first-or second-degree relative with autopsy negative SCD (1 point), and sudden infant death syndrome (1 point);

- Two genetic findings: genotype-positive ( 2 points) and mutation of undetermined significance in a culprit gene (1 point).

A score $\geq 4$ points is considered high probability, 3 points intermediate probability and $\leq 2$ points low probability of SQTS. For the individuals with 3 points, the authors recommend continued clinical and electrocardiographic vigilance in the proband and first-degree relatives.

These criteria when applied in the 61 reported cases of the cohort show a high sensitivity.

\section{Possible limitations of the score}

\section{The use of the Bazett's formula}

A criticism to the use of the Bazett's formula employed by the authors is based on the QT intervals not shortened if the heart rate is faster. Consequently, the Bazett's formula will overcorrect the QT interval significantly at any heart rate $>60 \mathrm{bpm}$, and attempts should always be made to record an ECG as close to $60 \mathrm{bpm}$ as possible by obtaining data from Holter monitoring or using a beta-blocker [19]. Rate-dependence of the QT interval was recognized 93 years ago by Henry Cuthbert Bazett [20], calculating the heart rate-corrected QT interval $\mathrm{QT}_{\mathrm{B}}$. This nonlinear formula, obtained from data in only 39 young men, is not 
Table 1. Congenital short QT syndrome variants. Modified from Courtesy Professor Charles Antzelevitch.

\begin{tabular}{|c|c|c|c|}
\hline & QTc duration [ms] & Gene (cardiac ion channel) & Reference \\
\hline SQT1 & $286 \pm 6$ & KCNH2 (IKr) & [6] \\
\hline SOT2 & 302 & KCNQ1 (IKs) & [7] \\
\hline SQT3 & $315-330$ & KCNJ2 (IK1) & [10] \\
\hline SQT4 & $331-370$ & CACNB2b (ICa) & [12] \\
\hline SQT5 & $346-360$ & CACNA1C (ICa) & [12] \\
\hline SQT6 & 329 & CACNA2D1 (ICa) & [13] \\
\hline SQT7 & $?$ & SCN5A & [20] \\
\hline
\end{tabular}

Calcium and sodium channel mutations (SOT4/SOT5/SOT6 and SQT7) produce a combined SQTS/Brugada syndrome phenotype (overlapping phenotype)

accurate and overcorrects at high heart rates and undercorrects at low heart rates [21]. Additionally, in congenital SQTS the QT interval is not affected by the heart rate [20]; in other words, in this channelopathy a discrete QT interval reduction is observed with increases in heart rate.

\section{Nonexistence of a control group}

The study validation has the limitation of not having a control group made up of apparently healthy subjects with shorter-than-normal QTc intervals [22].

\section{The exclusion of criteria with great diagnostic utility}

The stress test is another parameter that should have been included by the authors, because adaptation of the QT interval to increased heart rate is abnormal in patients with SQTS, unlike normal subjects with short QT intervals. Very short atrial and ventricular effective periods $(<140 \mathrm{~ms}$ and $<150 \mathrm{~ms}$ respectively) are highly suspicious for SQTS. Therefore, these electrophysiologic criteria should have been included in the score to distinguish SQTS from healthy people with short QT intervals.

\section{Exclusion of first or second degree relatives $\leq 40$ years old without autopsy}

The exclusion of the presence of SCD in a first or second degree relative $\leq 40$ years of age in whom autopsy was not made, should not be excluded as criterion.

\section{Exclusion of mixed subtypes}

The study validation presents the limitation of not having included subtypes that do not affect the potassium channels; that is, the ones that affect the calcium (SQT4, SQT5 and SQT6) and sodium channels (SQT7).
We share the view of Veltman and Borggrefe [23] that Gollob's score was clearly inspired by the diagnostic criteria for LQTS developed by Schwartz et al. [24] for LQTS: a 'Schwartz score' for SQTS.

In November 2012, Hong et al. [25] from The Second Affiliated Hospital of Nanchang University, China, identified the first variant of SQTS with concomitant Brugada-like pattern. This was associated with a mutation in the alpha subunit of the SCN5A gene causing a loss of function and considered variant 7 or SQT7. In many cases, multiple biophysical defects with mutations in the SCN5A gene caused mixed channelopathy syndromes of the sodium channel: overlap syndrome of cardiac sodium channelopathy [26]. If we employ a criterion encompassing variants with mixed phenotypes (overlapping phenotypes) it is reasonable to assume at least 7 variants of SQTS (Table 1).

Finally, we have recently observed the presence of $\mathrm{T}$ waves with particular features characterized by negative-positive or "minus-plus" polarity in some ECG tracings in the literature and in a recent family from Brazil (Fig. 3). This "minus-plus T-wave sign" appears as a biphasic negative/positive T wave following the QRS with absent ST segments (Figs. 4, 5). For now this electrocardiographic finding may have diagnostic value if the following question is considered: What is the utility of this finding? Does its presence help to make a diagnosis and/or prognosis? To answer this question it is necessary to systematically review published electrocardiographic tracings and Holters to determine the frequency of the sign and how its presence contributes to diagnosis or prognosis.

\section{Conclusions}

Congenital SQTS is a channelopathy without structural heart disease and considered an elec- 


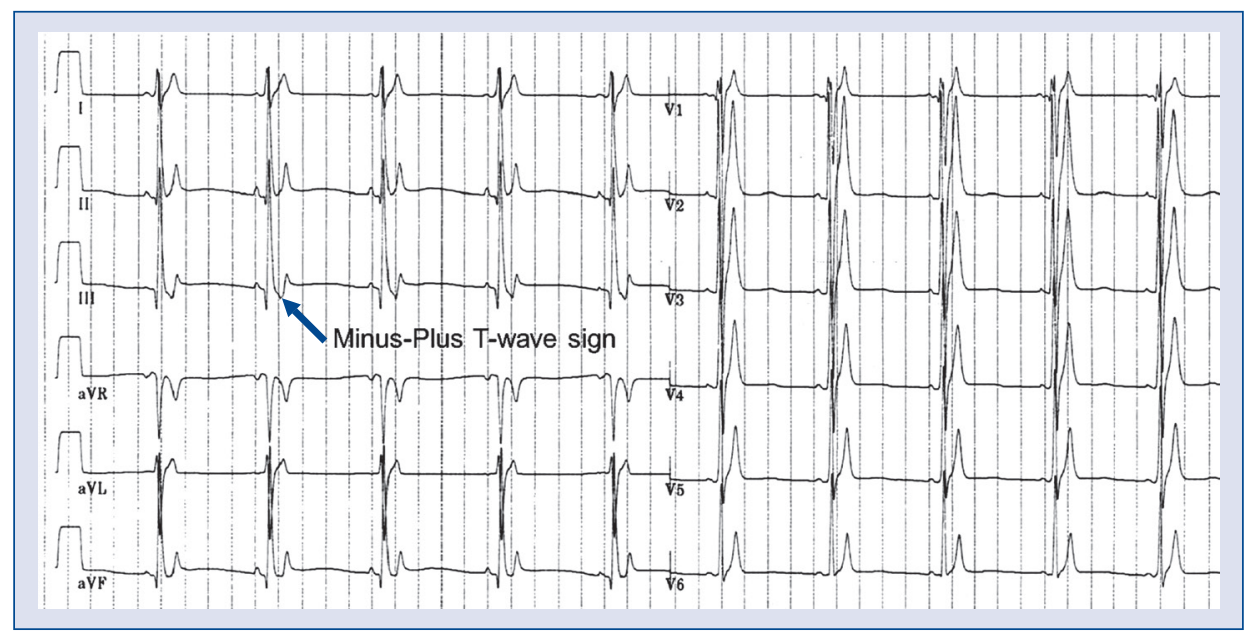

Figure 4. Very short QT intervals, absent or minimal ST segments, tall peaked pseudo-symmetrical T waves or "hyperkalemic like T waves". Additionally, in lead III "minus-plus T-wave sign" is observed.

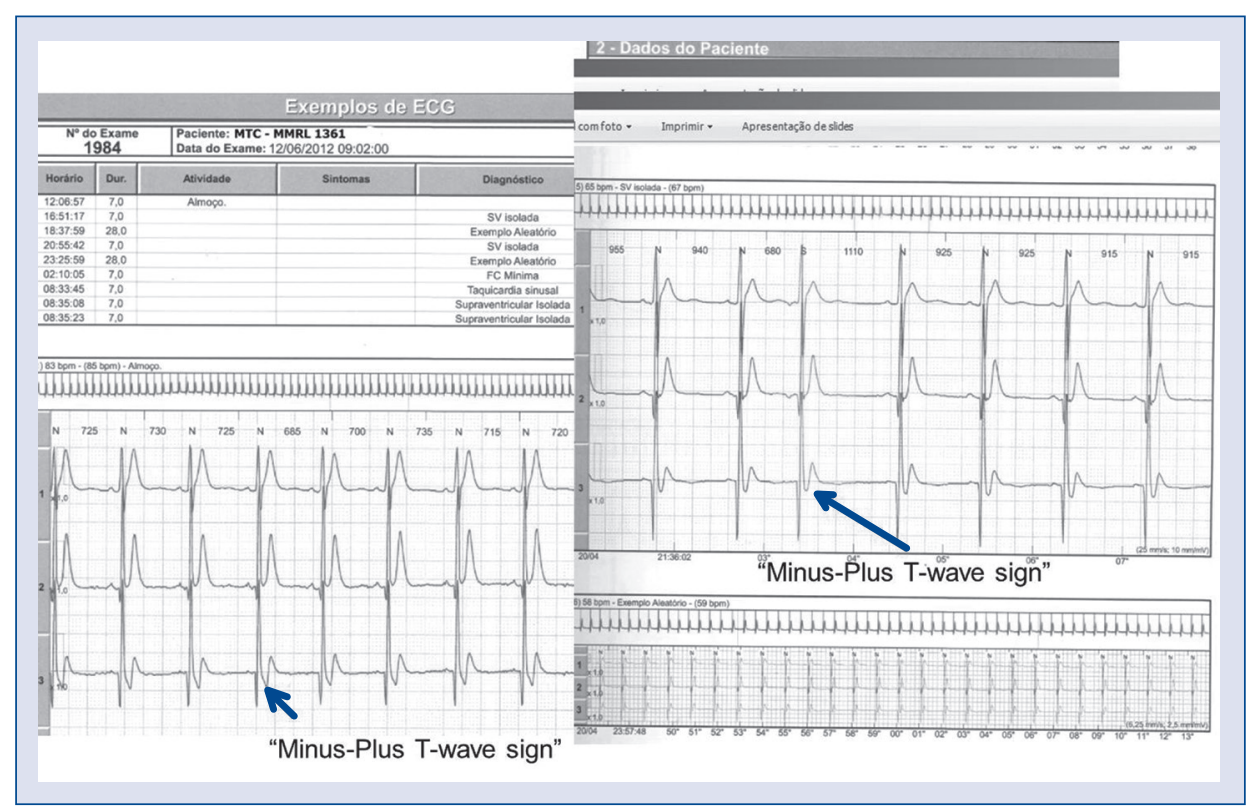

Figure 5. The "minus-plus T-wave signal" observed in a Holter recording in a patient from Latin America (Brazil).

trical heart disease. It is a rare autosomal familial syndrome of low penetrance associated with mutations in genes that control potassium, calcium or sodium channels and characterized by clinical, electrocardiographic and electrophysiological typical features, and negative autopsy or "mors sine materia" where molecular autopsy is mandatory $[27,28]$.
In this chronological historical review we considered the main landmarks and showed how science has constructed the gradual clarification of this fascinating channelopathy. It is important to highlight that many cases of idiopathic VF could occur due to SQTS, and that the diagnosis is not always perceived even by experienced colleagues.

Conflict of interest: none declared 


\section{References}

1. Pérez-Riera AR, Abreu LC, Yanowitz F et al. "Benign" early repolarization versus malignant early abnormalities: clinical-electrocardiographic distinction and genetic basis. Cardiol J, 2012; 19: 337-346.

2. Algra A, Tijssen JG, Roelandt JR. Pool J, Lubsen J. QT interval variables from 24 hour electrocardiography and the two year risk of sudden death. Br Heart J, 1993; 70: 43-48.

3. Bjerregaard P, Gussak I. Short QT syndrome. Ann Noninvasive Electrocardiol, 2005; 10: 436-440.

4. Gussak I, Liebl N, Nouri S, Bjerregaard P, Zimmerman F, Chaitman BR. Deceleration-Dependent Shortening of the QT interval: A New Electrocardiographic Phenomenon? Clin Cardiol, 1999; 22: 124-1126.

5. Gussak I, Brugada P, Brugada J et al. Idiopathic short QT interval: a new clinical syndrome? Cardiology, 2000; 94: 99-102.

6. Gaita F, Giustetto C, Bianchi F et al. Short QT Syndrome: A familial cause of sudden death. Circulation, 2003; 108: 965-970.

7. Schrimpf R, Wolpert C, Bianchi F et al. Congenital short QT syndrome and implantable cardioverter defibrillator treatment: Inherent risk for inappropriate shock delivery. J Cardiovasc Electrophysiol, 2003; 14: 1273-1277.

8. Brugada R, Hong K, Dumaine R et al. Sudden death associated with short-QT syndrome linked to mutations in HERG. Circulation, 2004; 109: 30-35.

9. Bellocq C, van Ginneken AC, Bezzina CR et al. Mutation in the KCNQ1 gene leading to the short QT-interval syndrome. Circulation, 2004; 109: 2394-2397.

10. Viskin S, Zeltser D, Ish-Shalom M et al. Is idiopathic ventricular fibrillation a short QT syndrome? Comparison of QT intervals of patients with idiopathic ventricular fibrillation and healthy controls. Heart Rhyth, 2004; 5: 587-591.

11. Bjerregaard P, Nallapaneni H, Gussak I. Short QT interval in clinical practice. J Electrocardiol, 2010; 43: 390-395.

12. Priori SG, Pandit SV, Rivolta I et al. A novel form of short QT syndrome (SQT3) is caused by a mutation in the $\mathrm{KCNJ} 2$ gene. Circ Res, 2005; 96: 800-807.

13. Anttonen O, Junttila J, Giustetto C et al. T-Wave morphology in short QT syndrome. Ann Noninvasive Electrocardiol, 2009; 14: 262-267.

14. Pérez-Riera AR, Ferreira C, Dubner SJ, Soares JD, Francis J. Brief review of the recently described short QT syndrome and other cardiac channelopathies. Ann Noninvasive Electrocardiol, 2005; 10: 371-377.

15. Antzelevitch C, Pollevick GD, Cordeiro JM et al. Loss-of-function mutations in the cardiac calcium channel underlie a new clinical entity characterized by ST-segment elevation, short QT intervals, and sudden cardiac death. Circulation, 2007; 115: 442-449.

16. Anttonen $\mathrm{O}$, Väänänen $\mathrm{H}$, Junttila J et al. Electrocardiographic transmural dispersion of repolarization in patients with inherited short QT syndrome. Ann Noninvasive Electrocardiol, 2008; 13: 295-300.

17. Templin C, Ghadri JR, Rougier JS et al Identification of a novel loss-of-function calcium channel gene mutation in short QT syndrome (SQTS6). Eur Heart J, 2011; 32: 1077-1088.

18. Gollob MH, Redpath CJ, Roberts JD. The short QT syndrome: proposed diagnostic criteria. J Am Coll Cardiol, 2011; 57: 802-812 .

19. Bjerregaard P. Proposed diagnostic criteria for short QT syndrome are badly founded. J Am Coll Cardiol, 2011; 58: 549-550.

20. Bazett HC. An analysis of the time-relations of electrocardiograms. Heart, 1920; 7: 353-370.

21. Salvi V, Karnad DR, Panicker GK, Kothari S. Update on the evaluation of a new drug for effects on cardiac repolarization in humans: issues in early drug development. Br J Pharmacol, 2010; 159: $34-48$.

22. Maluli HA, Meshkov AB. A short story of the short QT syndrome. Cleve Clin J Med, 2013; 80: 41-47.

23. Veltmann C, Borggrefe M. Arrhythmias: A 'Schwartz score' for short QT syndrome. Nat Rev Cardiol, 2011; 8: 251-252.

24. Schwartz PJ, Moss AJ, Vincent GM, Crampton RS. Diagnostic criteria for the long QT syndrome. An update. Circulation, 1993; 88: 782-784.

25. Hong K, Hu J, Yu J, Brugada R. Concomitant Brugada-like and short QT electrocardiogram linked to SCN5A mutation. Eur J Hum Genet, 2012; 20: 1189-1192.

26. Remme CA, Wilde AA, Bezzina CR. Cardiac sodium channel overlap syndromes: different faces of SCN5A mutations. Trends Cardiovasc Med, 2008; 18: 78-87.

27. Basso C, Carturan E, Pilichou K, Rizzo S, Corrado D, Thiene G. Sudden cardiac death with normal heart: molecular autopsy. Cardiovasc Pathol, 2010; 19: 321-325.

28. Tester DJ, Ackerman MJ. The role of molecular autopsy in unexplained sudden cardiac death. Curr Opin Cardiol, 2006; 21: 166-172. 